\title{
Gravitational Waves and Tidal Deformability of Neutron Stars
}

\author{
Young-Min KIM · Kyujin KWAK \\ Department of Physics, Ulsan National Institute of Science and Technology, Ulsan 44919, Korea \\ Yeunhwan LIM \\ Cyclotron Institute, Texas A\&M University, College Station, TX 77843, USA \\ Chang Ho Hyun \\ Department of Physics Education, Daegu University, Gyeongsan 38453, Korea \\ Chang-Hwan LEE* \\ Department of Physics, Pusan National University, Busan 46241, Korea \\ (Received 4 May 2018 : revised 15 May 2018 : accepted 15 May 2018)
}

\begin{abstract}
The gravitational waves (GW170817) produced during a binary neutron star inspiral, followed by a gamma-ray burst (GRB 170817A) and afterglows from X-ray to radio wavelength, were observed. By combining the distance obtained from gravitational waves with the red shift obtained from electromagnetic waves, even the Hubble constant was estimated. This indicates the start of new era of multimessenger astronomy. In addition to the masses of inspiralling neutron stars, the tidal deformability, which depends on the inner structures of neutron stars, has been estimated from gravitational waves. This confirms that even strong interactions can be tested by using gravitational waves. In this article, we review the effect of the tidal deformability of neutron stars on the gravitational waves produced during the inspiral process and discuss the implications of the detected tidal deformability for the neutron star's equations of state.
\end{abstract}

PACS numbers: 04.30.Tv, 26.60.Kp, 97.60.Jd

Keywords: Gravitational waves, Neutron star, Equation of state, Tidal deformability

\section{중력파와 중성자별 조력 변형성}

\author{
김영민 · 곽규진
}

울산과학기술원 물리학과, 울산 44919, 대한민국

\section{임연환}

Cyclotron Institute, Texas A\&M University, College Station, TX 77843, USA

\section{현창호}

대구대학교 물리교육과, 경산 38453 , 대한민국

\section{이창환*}

부산대학교 물리학과, 부산 46241 , 대한민국 
(2018년 5월 4일 받음, 2018년 5월 15 일 수정본 받음, 2018년 5 월 15 일 게재 확정)

\begin{abstract}
중성자별 병합과정에서 발생한 중력파 GW170817과 감마선폭발 GRB $170817 \mathrm{~A}$ 및 엑스선에서 전파에 이르는 다양한 파장 영역의 후광 관측이 이루어졌다. 중력파로부터 추정된 GW170817의 거리와 후광 관측의 적색편이를 이용한 허블상수 측정의 성공은 다중신호천문학의 시작을 알리는 계기가 되고 있다. 또한 중력파 분석을 통하여 충돌하는 두 중성자별의 질량 뿐 아니라 중성자별 내부 구조에 의존하는 조력 변형성 측정에 성공함으로서 중력파를 이용하여 강상호작용의 효과를 확인하는 단계에 이르렀다. 이 논문에서는 중성자별의 조력 변형성이 두 중성자별의 병합과정에서 발생하는 중력파에 미치는 영향을 살펴보고, 이번 중력파 관측에서 얻어진 조력 변형성 값이 중성자별의 상태방정식 연구에 미치는 영향을 논의한다.
\end{abstract}

PACS numbers: 04.30.Tv, 26.60.Kp, 97.60.Jd

Keywords: 중력파, 중성자별, 상태방정식, 조력 변형성

\section{I. 다중신호천체물리 시대의 중성자별 연구}

라이고(Laser interferometer gravitational-wave observatory, LIGO) 는 중력파 GW150914 검출을 시작으로 두 블랙홀의 병합 과정에서 발생한 중력파를 다수 검출함으로 써 중력파천문학 분야의 개척을 주도하였다 [1-12]. 중력파 검출을 통하여, 기존의 전자기파로는 관측이 되지 않은, 새로운 질량 영역의 블랙홀의 존재가 확인됨으로써 중력파 천문학은 은하 및 별의 진화 연구에 새로운 활력소가 되고 있다. 블랙홀 충돌에서 발생한 중력파의 성공적인 검출은 중성자별 충돌에서 발생한 중력파 검출에 대한 기대로 이 어졌다. 블랙홀과 달리 중성자별은 강상호작용 및 전자기 상호작용을 하는 물질로 구성되어 있으므로, 두 중성자별의 병합과정에서 중력파 뿐 아니라 다양한 파장의 전자기파가 발생할 것으로 예측되었다. 특히 지속시간이 짧은 감마선폭 발 (Gamma-ray burst, GRB) 의 원인으로 두 중성자별의 충돌이 지목받고 있으므로, 중력파와 감마선폭발의 동시 관 측은 중성자별 충돌의 결정적인 증거로 제시되었다. 이러한 시점에 이루어진 중력파 $(\mathrm{GW} 170817)$ 와 감마선폭발 $(\mathrm{GRB}$ $170817 \mathrm{~A})$ 및 이어진 전자기파 후광(SSS17a/AT 2017gfo) 관측은 다중신호천문학의 시작을 알리는 계기가 되었다 $[13,14]$. 다중신호 관측 결과, 가시광선, 적외선 및 엑스선의 시간에 대한 세기 변화 분석을 통하여 이번 폭발이 킬로노바 현상의 첫번째 관측 증거로 제시되었고 [15], 중력파로부터 추정된 중성자별 쌍성계의 거리와 전자기파로부터 추정된 적색편이를 결합하여 허블상수를 추정할 수 있었다 [16].

중성자별 충돌에 의한 중력파 GW170817의 관측 시간은 약 58 초로서 블랙홀 충돌에 의한 중력파 지속 시간에 비하여 매우 길다 [13]. 이는 중력파 신호의 세기를 결정하는 쳐프 질량 (chirp mass) 은 블랙홀 충돌에 비해 작지만 중성자별

\footnotetext{
*E-mail: clee@pusan.ac.kr
}

쌍성계의 거리가 $40 \mathrm{Mpc}$ 으로서 상대적으로 가깝기 때문이 다. 결과적으로 긴 중력파 지속시간은 중력파의 위상차이 누적을 통한 중성자별의 조력 변형성 (tidal deformability) 측정을 가능케하였다 [13]. 조력 변형성은 외부 4 중극자 중력장의 영향으로 중성자별의 4 중극자 모멘트가 변하는 정도를 나타내며 중성자별 내부 상태방정식에 의존하는 양이다.

중력파 관측으로 구한 조력 변형성은 중성자별 상태방정 식을 테스트할 수 있는 새로운 가능성을 제시하였다 [17-25].

중성자별은 질량은 태양 질량의 2 배 정도인 반면 반경은 $\mathcal{O}(10 \mathrm{~km})$ 인 고중력천체로서, 중심부에 형성되는 물질은 밀도가 보통 핵밀도 $\left(n_{0} \approx 0.16 \mathrm{fm}^{-3}\right)$ 의 수 배에 이르러 강상호작용이 지배하고 있다. 이러한 고밀도 상태는 지상의 실험실에서 구현이 어려우므로, 중성자별은 고밀도물질 의 강상호작용을 검증할 수 있는 매우 중요한 천체이다. 중력파에 의한 조력 변형성 측정 이전의 중성자별 연구는 중성자별의 질량 및 반경과 같은 거시적인 물리량을 중심 으로 이루어졌다. 특히 중성자별의 최대 질량은 중성자별 상태방정식을 검증할 수 있는 주요 물리량으로서 $2.0 M_{\odot}$ $\left(M_{\odot}=\right.$ 태양 질량) 질량을 가진 중성자별의 발견은 [ 26,27$]$, 중성자별 최대 질량 예측값이 이 보다 작은 많은 상태방정식 을 제외시키는 계기가 되었다. 또한 최근의 엑스선 쌍성계 관측 결과는 중성자별의 질량과 반경을 동시에 측정할 수 있는 가능성을 보여 주어 주목을 받고 있다 [28,29]. 이러한 상황에서 중력파 관측으로 조력 변형성을 측정함으로써 중성자별의 질량과 반경 뿐 아니라 내부 구조를 검증할 수 있는 단계에 이르렀다 [13].

이 논문은 중성자별 상태방정식의 과학적 의미와 중요성, 조력 변형성과 중력파의 상관 관계, 그리고 조력 변형성 관측이 중성자별 상태방정식 연구에 미치는 영향을 다루며 다음과 같이 구성되었다. II장에서는 본 연구에서 사용된 대표적인 중성자별 상태방정식의 주요 특성을 살펴보고, 


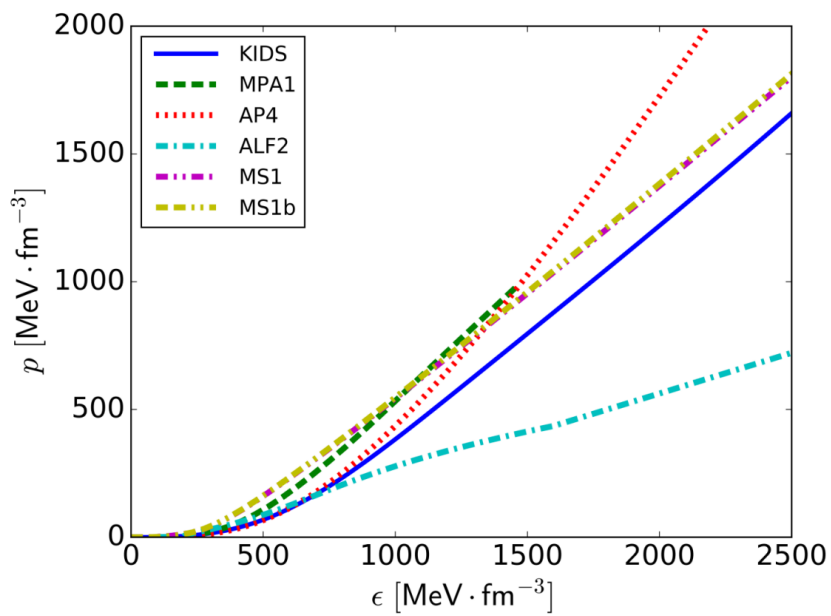

Fig. 1. (Color online) Pressure $(p)$ vs. energy density $(\epsilon)$ for various nuclear equations of state. In general, slopes of the curves $\left(d p / d \epsilon=c_{s}^{2}\right)$ for stiff equations of state (MS1, MS1b) are larger than those of soft ones for $\epsilon<1500$.

III장에서는 중성자별 조력 러브수(tidal Love number)와 조력 변형성 방정식을 정리한다. IV장에서는 중성자별 조 력 변형성이 중력파에 미치는 영향을 살펴보고, $\mathrm{V}$ 장에서는 중성자별 조력 변형성과 상태방정식과의 상관 관계를 살펴 본다. 마지막으로 VI장에서는 중력파천문학 및 다중신호 천문학 시대에 중력파를 통한 중성자별 구조 연구의 전망을 살펴본다.

\section{II. 중성자별 상태방정식}

이 장에서는 조력 변형성 계산에 필요한 중성자별 내부 상태방정식을 소개하고 대표적인 상태방정식의 결과로 얻 어지는 중성자별의 질량과 반경의 상관 관계를 비교한다.

중성자별 내부 구조는 고밀도 물질을 구성하는 강입자의 종류, 온도, 열전달율, 자기장 등의 함수이다. 중성자별의 냉각과정과 전자기파 펄서 방출 과정은 온도, 열전달율, 자기장 등에 크게 의존하지만, 전자기 상호작용이 강상호 작용보다 매우 작아서, 이들이 중성자별 내부 구조에 미치 는 영향은 무시할 수 있으며, 중성자별은 고중력 천체로서 회전에 의한 일그러짐이 작다. 따라서 일반적으로 온도가 0 이고 구대칭 구조인 중성자별의 상태방정식이 연구되고 있다.

온도가 0이고 구대칭 구조의 중성자별 상태방정식 $p(r)$ 과 $\epsilon(r)$ 은 아래 식으로부터 구할 수 있다.

$$
\begin{aligned}
\frac{d p}{d r} & =-e^{2 \chi}(\epsilon+p)\left(\frac{m}{r^{2}}+4 \pi r p\right) \\
\frac{d m}{d r} & =4 \pi r^{2} \epsilon .
\end{aligned}
$$

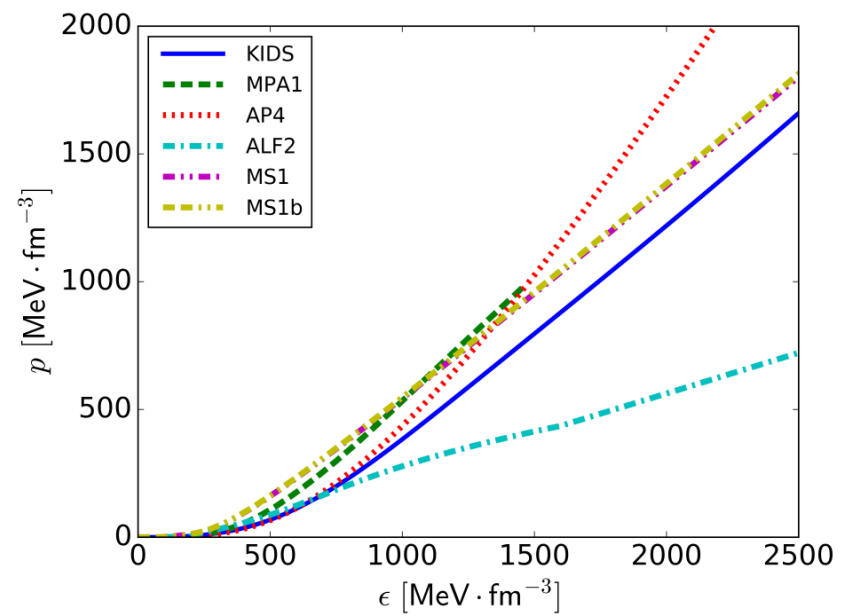

Fig. 2. (Color online) Mass vs. central density $\left(\rho_{c} / \rho_{0}\right)$ of neutron stars for various equations of state. Central densities of stiff equations of state (MS1, MS1b) are smller than those of harder ones.

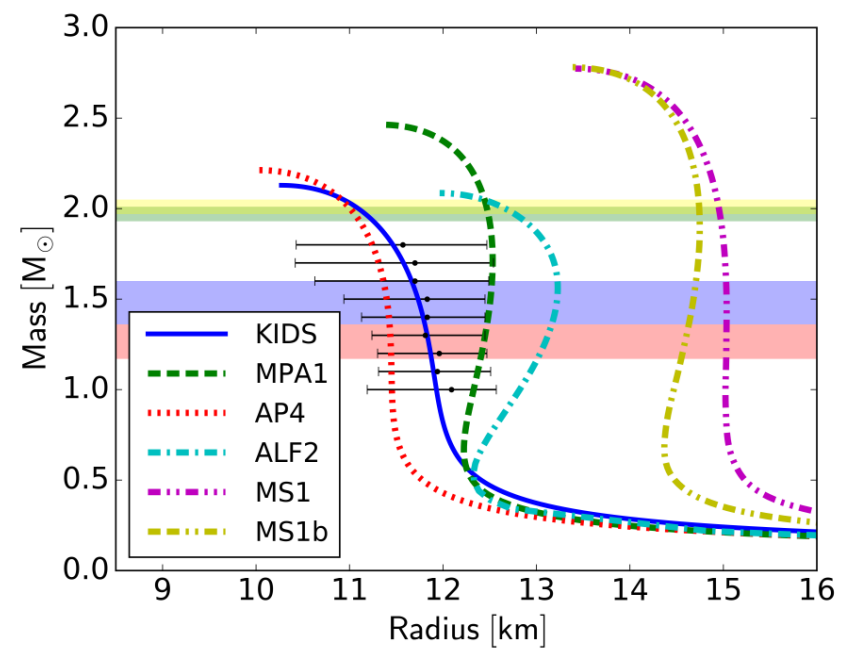

Fig. 3. (Color online) Mass vs. Radius of neutron stars for various neutron star equations of state [30,33-36]. Yellow and green regions indicate $2 M_{\odot}$-constraint [26, 27]. Blue (red) region indicates a neutron star mass M1(M2) in binary neutron stars estimated by GW170817 analysis [13]. Horizontal error bars at around $\mathrm{R} \sim 12 \mathrm{~km}$ indicate probable radius of a neutron star estimated from X-ray bursts observation [28].

여기서

$$
e^{2 \chi}=\left(1-\frac{2 m}{r}\right)^{-1}
$$

이고, $p$ 와 $\epsilon$ 은 평형상태인 중성자별 내부의 반경 $r$ 인 지점 에서 압력과 에너지밀도이며 $m$ 은 $r$ 내부에 포함된 질량을 나타낸다.

Fig. 1은 다양한 상태방정식의 압력 $(p)$ 과 에너지밀도 $(\epsilon)$ 의 상관관계를 나타낸다. Figs. 2,3 은 중성자별의 중 
심밀도 $\left(\rho_{c}\right)$ 및 반경 $(R)$ 과 질량 $(M)$ 의 관계를 보여준다. 본 연구에서는 비교를 위하여 중성자별의 최대 질량이 관 측으로 확인된 $2 M_{\odot}$ 를 넘는 중성자별 상태방정식 중에 서 단단한 (stiff) 상태방정식 4 개와 연한 (soft) 상태방정 식 2 개를 선택하였다. KIDS는 비상대론적 핵에너지밀 도함수(nuclear energy-density functional) 모델로서 [30, 31], 밀도함수 (density functional) 를 $\rho^{1 / 3}$ 의 함수로 전개 하여 핵물질을 기술하고 있으며, 11 개의 핵물질 실험 조 건을 만족한다 [32]. MPA1은 상대론적 브루크너-하트리폭(Brueckner-Hartee-Fock) 모델이고 [33], AP4는 변분 사슬합계 (variation chain summation) 를 이용한 아르곤 (Argonne) $v_{18}$ (AV18) 두 핵자 상호작용 모델에 3 체상호 작용(three nucleon interaction) 을 위한 UIX 모델과 상대 론적 보정항 $\delta v$ 가 추가된 상태방정식이다 [34]. ALF2는 핵물질 (nuclear matter) 과 쿼크물질 (quark matter)를 고 려한 혼합(hybrid) 상태방정식으로서 [35] 핵물질은 APR (AV18+UIX) 모델을 사용하고, 쿼크물질은 $\mathrm{QCD}$ 보정항 이 들어간 MIT bag 모델이 사용되었다. MS1과 MS1b 는 상대론적 평균장 이론(relativistic mean field theory) 을 이용한 상태방정식이다 [36]. ALF2을 제외한 나머지 상태방정식들은 핵자간 상호작용만을 고려하고 있다.

Fig. 3에서 연한 상태방정식(KIDS, MPA1, AP4, ALF2) 은 중성자별의 반경이 $11 \sim 13 \mathrm{~km}$ 에 주로 분포하고 있으며 최대질량은 $2 \sim 2.5 M_{\odot}$ 인 반면, 단단한 상태방정식 $(\mathrm{MS} 1$, $\mathrm{MS} 1 \mathrm{~b})$ 은 중성자별 반경이 $14 \sim 16 \mathrm{~km}$ 에 분포하고 있으며 최대 질량은 $2.5 M_{\odot}$ 을 넘는다.

\section{III. 중성자별 조력 변형성}

중성자별의 조력 변형성 $\lambda$ 는, 안정적이고 구대칭 구조 를 가진 중성자별이 정적인 외부 4 중극자 중력장 (static external quadrupolar gravitational field) 의 영향으로 4 중 극자 모멘트 (induced quadrupole moment) 가 유도될 때, 외부 4 중극자 중력장과 유도된 중성자별 4 중극자 모멘트 의 관계를 나타내는 변수로 차원이 있는 변수이다. 조력 변형성 $\lambda$ 와 관련된 변수로 차원이 없는 조력 러브수 $\left(k_{2}\right)$ 및 차원없는 조력 변형성 $\Lambda$ 가 함께 사용되고 있다. 이 장에서는 중성자별 조력 변형성 및 조력 러브수의 물리적 특성을 먼저 검토하고, 일반상대론에서 유도된 중성자별의 조력 러브수 방정식을 소개한다. 조력 변형성 $(\lambda, \Lambda)$ 는 조력 러브수로부터 쉽게 구할 수 있다.

\section{1. 조력 변형성과 조력 러브수}

두 종류의 조력 변형성 $(\lambda, \Lambda)$ 및 조력 러브수 $\left(k_{2}\right)$ 의 주요 특성에 차이가 있으므로, 중성자별 조력 변형성과 중력파의 상관관계에 대한 깊이 있는 이해를 위하여, 아래 각 변수의 주요 특성을 정리한다.

\section{1) 조력 변형성 $\lambda$}

조력 변형성 $\lambda$ 는 아래와 같은 일반상대론의 근사를 통해 정의된다 $[17,18]$.

$$
\begin{aligned}
-\frac{\left(1+g_{t t}\right)}{2}= & -\frac{G m}{c^{2} r}-\frac{3 G}{2 c^{2}} \frac{Q_{i j}}{r^{3}} n^{i} n^{j}+\cdots+\frac{\mathcal{E}_{i j}}{2 c^{2}} r^{2} n^{i} n^{j} \\
& +\cdots
\end{aligned}
$$

위에서 $n^{i}=x^{i} / r$ 이고, 중성자별의 밀도변화 $\delta \rho$ 에 의한 중력자별의 4 중극자 모멘트 $Q_{i j}$ 는 아래와 같이 표현된다.

$$
Q_{i j}=\int d^{3} x \delta \rho(x)\left(x_{i} x_{j}-\frac{1}{3} r^{2} \delta_{i j}\right) .
$$

외부 중력퍼텐셜 $\Phi_{\mathrm{ext}}$ 에 의한 4 중극자 중력장 $\mathcal{E}_{i j}$ 는 중력 포텐셜의 공간에 대한 편미분으로 주어진다.

$$
\mathcal{E}_{i j}=\frac{\partial^{2} \Phi_{\mathrm{ext}}}{\partial x^{i} \partial x^{j}} .
$$

여기서 조력 변형성 $\lambda$ 는

$$
Q_{i j}=-\lambda \mathcal{E}_{i j}
$$

로 정의되며 $\lambda$ 의 차원이 $\left[r^{5} / G\right]=\left[\mathrm{g} \mathrm{cm}^{2} \mathrm{~s}^{2}\right]$ 로 주어짐을 알 수 있다. 일반적으로 $\lambda$ 의 값은 $\mathcal{O}\left(10^{36} \mathrm{~g} \mathrm{~cm}^{2} \mathrm{~s}^{2}\right)$ 으로, 외부 4 중극자 중력장과 중성자별의 4 중극자 모멘트 값을 직접 비교하기에 좋은 변수이다.

\section{2) 조력 러브수 $k_{2}$}

조력 러브수는 물리적 차원이 없는 양으로 외부 4 중극자 중력장에 의한 중성자별의 4 중극자 모멘트 변화를 보다 직관적으로 추정할 수 있는 기본적인 변수이다 $[17,18,37]$. $k_{2}$ 의 값은 $\mathcal{O}(0.1)$ 로서 조력에 의한 변형 정도를 나타내며 $\lambda$ 와 아래 관계가 있다 $[18,20]$.

$$
k_{2}=\frac{3}{2} G \lambda R^{-5} \text {. }
$$

여기서 $R$ 은 중성자별의 반경이다. 
$k_{2}$ 는 중성자별의 밀집도 변수 (compactness parameter) $C\left(\equiv G M / R c^{2}\right)$ 및 중성자별 내부 밀도 구성에 의존하는 데, 일반적으로 작은 질량 및 큰 질량에서 감소하는 형태를 갖는다.

질량이 큰 중성자별의 경우, 질량이 증가함에 따라 반경이 작아지고 밀집도가 증가하여 외부 중력장에 의한 중성자별 의 4 중극자 모멘트 변화가 감소하므로 $k_{2}$ 가 감소하게 된다. 반경이 쉬바르차일드반경으로 감소된다면 블랙홀이 되어 $C$ 는 최대값 0.5 가 되고 $k_{2}=0$ 이 된다. 반면에 질량이 작은 중성자별의 경우, 질량 감소에 따라 반경이 증가하여 밀집도가 감소하기는 하지만, 중성자별 중심부에 대부분의 질량이 모여서 결과적으로 $k_{2}$ 가 감소하게 된다 [18].

\section{3) 차원없는 조력 변형성 $\Lambda$}

중력파의 조력 변형성 측정은 레이져 간섭계를 통과하는 중력파의 위상차이를 이용하므로, 중력파 위상에 기여하는 정도를 나타내는 것은 물리적 차원이 없는 조력 변형성 $\Lambda$ 이다. 따라서 중력파 분석에는 주로 $\Lambda$ 가 사용되고 있는데 $[13,19]$ 이는 다음과 같이 정의된다.

$$
\begin{aligned}
\Lambda & =G \lambda\left(\frac{c^{2}}{G M}\right)^{5}=\frac{2}{3}\left(\frac{R c^{2}}{G M}\right)^{5} k_{2} \\
& \approx 9495 \times\left(\frac{R / 10 \mathrm{~km}}{M / M_{\odot}}\right)^{5} k_{2} .
\end{aligned}
$$

위에서 $M$ 과 $M_{\odot}$ 는 중성자별과 태양의 질량이다. 중성자 별의 질량과 반경의 비 $C$ 값의 변화가 크므로 $\Lambda$ 는 중성자별 의 질량에 따라 매우 크게 변한다. 일반적으로 중성자별의 질량이 감소할수록 반경이 증가하고 결과적으로 $\Lambda$ 가 매우 빠르게 증가하므로, 작은 질량의 중성자별이 충돌할 때 중 력파에 의한 조력 변형성 측정이 용이하게 된다. 식 (8)의 큰 계수도 중력파를 이용한 중성자별 조력 변형성 측정이 가능한 주요 원인이다.

\section{2. 중성자별의 조력 러브수 $k_{2}$ 방정식}

일반적으로 조력 러브수를 먼저 계산하고 이로부터 조력 변형성을 구하므로, 이 장에서는 조력 러브수 방정식을 소 개한다.

외부 4 중극자 중력장에 의해 구 대칭 구조의 중성자별에 작은 4 중극자 모멘트가 유도될 때 중성자별 내부 및 외부 의 시공간 구조는 구면 조화 (spherical harmonics) 함수를 $l=2$ 항까지 근사한 아래의 방정식을 이용하여 얻을 수
있다 $[17,18,20,21]$. 편의상 다음 식에서는 $G=c=1$ 인 단위를 사용한다.

$$
\begin{aligned}
d s^{2}= & -e^{2 \nu(r)}\left[1+H(r) Y_{20}(\theta, \phi)\right] d t^{2} \\
& +e^{2 \chi(r)}\left[1-H(r) Y_{20}(\theta, \phi)\right] d r^{2} \\
& +r^{2}\left[1-K(r) Y_{20}(\theta, \phi)\right]\left(d \theta^{2}+\sin ^{2} \theta d \phi^{2}\right) .
\end{aligned}
$$

위에서 $K(r)$ 과 $H(r)$ 은 다음 관계에 있으며,

$$
K^{\prime}(r)=H^{\prime}(r)+2 H(r) \nu^{\prime}(r),
$$

$H(r)$ 은 다음 미분방정식을 만족한다.

$$
\begin{aligned}
& \left(-\frac{6 e^{2 \chi}}{r^{2}}-2\left(\nu^{\prime}\right)^{2}+2 \nu^{\prime \prime}+\frac{3}{r} \chi^{\prime}+\frac{7}{r} \nu^{\prime}-2 \nu^{\prime} \chi^{\prime}\right. \\
& \left.+\frac{f}{r}\left(\nu^{\prime}+\chi^{\prime}\right)\right) H+\left(\frac{2}{r}+\nu^{\prime}-\chi^{\prime}\right) H^{\prime}+H^{\prime \prime}=0 .
\end{aligned}
$$

임의의 함수 $\xi(r)$ 에 대해 $\xi^{\prime}=d \xi / d r$ 을 나타내고, 함수 $f$ 는

$$
\delta \epsilon=f \delta p
$$

로 주어진다. 중성자별 내부 물질 분포 변화가 작은 경우 $f=d \epsilon / d p$ 에 해당하며 중성자별 내부 소리 속력 (sound speed) 제곱은 $c_{s}^{2}=f^{-1}$ 로 주어진다 [38].

중성자별의 조력 러브수를 구하기 위해서는 구대칭 구조 의 중성자별 상태방정식 $\epsilon(r), p(r)$ 과 함께 중성자별 내부의 $H(r)$ 을 동시에 구해야한다. 식 (1)의 결과를 이용하여 구한 중성자별 상태방정식을 이용하면, 중성자별 내부 $(r<R)$ 에서 $\nu^{\prime}$ 과 $\chi^{\prime}$ 을 다음과 같이 구할 수 있다.

$$
\begin{aligned}
\nu^{\prime} & =e^{2 \chi}\left(\frac{m}{r^{2}}+4 \pi r p\right), \\
\chi^{\prime} & =e^{2 \chi}\left(-\frac{m}{r^{2}}+4 \pi r \epsilon\right) .
\end{aligned}
$$

위 결과를 이용하여 식 (11)로부터 중성자별 내부에서 $H(r)$ 의 2 차 미분방정식을 얻을 수 있다.

$$
H^{\prime \prime}+H^{\prime}\left[\frac{2}{r}+\mathcal{Q}_{1}(r)\right]+H\left[\mathcal{Q}_{0}(r)-4\left(\nu^{\prime}\right)^{2}\right]=0 .
$$

위 식에서 $\mathcal{Q}_{i}(r)$ 은 아래와 같이 주어진다.

$$
\begin{aligned}
& \mathcal{Q}_{1}(r)=e^{2 \chi}\left[\frac{2 m}{r^{2}}-4 \pi r(\epsilon-p)\right], \\
& \mathcal{Q}_{0}(r)=e^{2 \chi}\left[4 \pi(5 \epsilon+9 p)+4 \pi f(\epsilon+p)-\frac{6}{r^{2}}\right]
\end{aligned}
$$

식 (15) 에서 중성자별 중심부에서 $H(r)$ 은 아래와 같이 근 사됨을 확인할 수 있다.

$$
\lim _{r \rightarrow 0} H(r)=a_{0} r^{2} .
$$




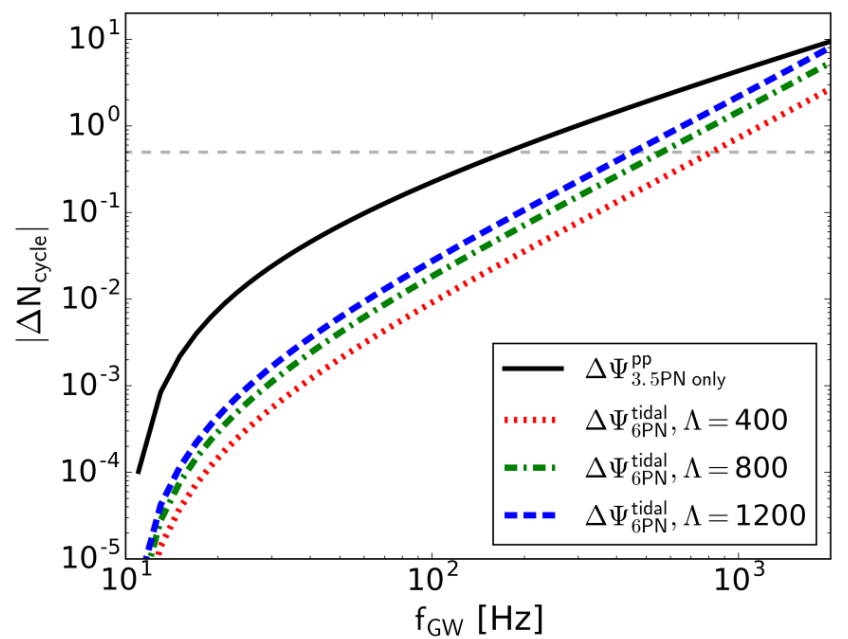

Fig. 4. (Color online) The number of wave cycles accumulated from $10 \mathrm{~Hz}$ to the final frequency of gravitational waves $\left(f_{\mathrm{GW}}\right)$. Horizontal dashed line indicates $\Delta N_{\text {cycle }}=0.5$ above which the contributions become significant for the measurements from gravitational waves.

$a_{0}$ 는 중성자별의 변형 정도를 나타내는데, $k_{2}$ 는 $a_{0}$ 와 무관 하게 얻어진다. 중성자별 외부 $(r>R)$ 에서는 $\epsilon=p=0$ 이고 $m=M$ 으로 주어지므로, 식 (15)의 해는 부 르장드르 함수(associate Legendre function) 로 주어진다.

$$
Q_{2}^{2}(r / M-1), P_{2}^{2}(r / M-1)
$$

중성자별 표면 $(r=R)$ 의 경계 조건으로부터 다음과 같은 $k_{2}$ 방정식을 얻을 수 있다.

$$
\begin{aligned}
k_{2} & =\frac{8 C^{5}}{5}(1-2 C)^{2}[2+2 C(y-1)-y] \mathcal{Z}^{-1} \\
\mathcal{Z} & =2 C[6-3 y+3 C(5 y-8)] \\
& +4 C^{3}\left[13-11 y+C(3 y-2)+2 C^{2}(1+y)\right] \\
& +3\left(1-2 C^{2}\right)[2-y+2 C(y-1)] \ln (1-2 C)
\end{aligned}
$$

위에서 $C=M / R$ 이고 $y=\left.\left(r H^{\prime} / H\right)\right|_{r=R}$ 는 중성자별 표 면에서의 값이다 $[17,18,20,21]$.

\section{IV. 중력파와 조력 변형성}

이 장에서는 조력 변형성이 중력파의 위상에 기여하는 정도를 소개하고 중력파를 이용하여 조력 변형성을 측정할 수 있는 가능성을 소개한다.

레이저 간섭계 중력파 관측소에서는 검출된 중력파의 위상차이를 누적하여 조력 변형성을 구할 수 있다. 중력파 신호는 고정 위상 근사(stationary phase approximation)
를 이용하여 분석을 하는데, 이 근사에서 주어진 주파수 $f$ 에서 중력파 신호는 다음과 같이 주어진다 [19].

$$
\tilde{h}_{T}(f)=\mathcal{A} f^{-7 / 6} e^{i \Psi_{T}}(f) .
$$

$\mathcal{A}$ 는 신호대잡음비 $(\mathrm{SNR})$ 에 비례하는 상수로 중력파원 거 리, 질량 및 궤도방향의 함수이다. 현재 중력파 검출에서 고려되고 있는 중력파 위상은 다음과 같이 여러 항으로 구 성이 된다.

$$
\begin{aligned}
\Psi_{T}(f)= & \phi_{c}+2 \pi f t_{c}+\frac{3}{128 \eta v^{5}}\left(\Delta \Psi_{3.5 \mathrm{PN}}^{\mathrm{pp}}+\Delta \Psi_{3 \mathrm{PN}}^{\mathrm{spin}}\right. \\
& \left.+\Delta \Psi_{2 \mathrm{PN}}^{\mathrm{ecc} .}+\Delta \Psi_{6 \mathrm{PN}}^{\mathrm{tidal}}+\Delta_{6 \mathrm{PN}}^{\mathrm{tm}}\right)
\end{aligned}
$$

위에서 $\eta=M_{1} M_{2} / M_{\mathrm{tot}}^{2}, M_{\mathrm{tot}}=M_{1}+M_{2}$ 이고, $t_{c}$ 와 $\phi_{c}$ 는 병합 때의 시간과 위상을 나타내는 상수로서 결과에 영향을 미치지는 않는다. $v \equiv\left(\pi M_{\mathrm{tot}} f\right)^{1 / 3}$ 는 포스트뉴턴근사 $(\mathrm{PN}$; post Newtonian) 의 차수를 결정하는 변수로서, $\mathrm{nPN}$ 은 $v^{2 n}$ 항까지 포함한다. $\Delta \Psi^{\mathrm{pp}}, \Delta \Psi^{\mathrm{spin}}, \Delta \Psi^{\mathrm{ecc}}, \Delta \Psi^{\mathrm{tm}}$ 은 각각, 표준 점입자근사(standard point-particle approximation), 스핀(spin), 이심률 (eccentricity) 및 $\eta \rightarrow 0$ 인 테스트 질량 (test mass) 근사를 이용한 고차항의 기여에 의한 위상차이 를 나타낸다 [19]. 조력 변형성에 의한 위상차이는 $5 \mathrm{PN}\left(v^{10}\right)$ 부터 시작하며, $6 \mathrm{PN}$ 까지 포함한 $\Delta_{6 \mathrm{PN}}^{\mathrm{tidal}}$ 은 다음과 같다 $[19$, $23]$.

$$
\Delta \Psi_{6 \mathrm{PN}}^{\mathrm{tidal}}=-\frac{39}{2} \tilde{\Lambda} v^{10}+v^{12}\left(\frac{6595}{364} \delta \tilde{\Lambda}-\frac{3115}{64} \tilde{\Lambda}\right) .
$$

쌍성계의 조력 변형성 $\tilde{\Lambda}$ 는 두 중성자별의 조력 변형성 $\left(\Lambda_{1,2}\right)$ 와 다음의 관계로 주어지며 $[18,22]$,

$$
\tilde{\Lambda}=\frac{16}{13} \frac{\left(M_{1}+12 M_{2}\right) M_{1}^{4} \Lambda_{1}+\left(M_{2}+12 M_{1}\right) M_{2}^{4} \Lambda_{2}}{\left(M_{1}+M_{2}\right)^{5}}
$$

$\delta \tilde{\Lambda} / \tilde{\Lambda}$ 는 0.01 보다 작은 양으로 무시할 수 있다 $[19,21,23]$. $M_{1} \geq M_{2}$ 인 경우 $\tilde{\Lambda}$ 를 다음과 같이 대칭질량비 $\eta$ 의 함수로 나타낼 수 있다 $[19,23]$.

$$
\begin{aligned}
\tilde{\Lambda}= & \frac{8}{13}\left[\left(1+7 \eta-31 \eta^{2}\right)\left(\Lambda_{1}+\Lambda_{2}\right)\right. \\
& \left.+\sqrt{1-4 \eta}\left(1+9 \eta-11 \eta^{2}\right)\left(\Lambda_{1}-\Lambda_{2}\right)\right] .
\end{aligned}
$$

질량이 같은 중성자별로 구성된 쌍성계의 경우 $\tilde{\Lambda}=\Lambda_{1}=$ $\Lambda_{2}$ 이다. 비록 $\Delta \Psi^{\mathrm{tidal}}$ 이 $5 \mathrm{PN}$ 부터 시작하여, 다른 항에 비해 PN 차수는 높지만, 식 (8) 에 주어진 $\Lambda$ 의 큰 계수는 중력파에 의한 조력 변형성 측정을 가능하게 한다. 초기 나선궤도(in-spiral) 단계에서 위상 누적에 고려되는 주파수 범위는 $f=10 \sim 1000 \mathrm{~Hz}$ 인데, 일반적으로 $10 \mathrm{~Hz}$ 에서 수 백 $\mathrm{Hz}$ 까지 위상차이를 누적하면 $\tilde{\Lambda}$ 를 측정할 수 있을 것으 
로 예상된다. 단, 주파수가 커질수록 높은 차수의 기여도가 증가하므로 오차도 증가한다.

Fig. 4 는 어드밴스드 라이고의 저주파영역 한계인 $f_{0}=10$ $\mathrm{Hz}$ 부터 중력파 주파수 $\left(f_{\mathrm{GW}}\right)$ 까지 누적된 파동의 반복수 (number of wave cycles) 차이 $\Delta N_{\text {cycle }}$ 을 보여주고 있다. $\Delta N_{\text {cycle }}$ 은 푸리에 변환한 중력파형의 주파수 도메인에서의 기여를 고려한 것으로서, $\Delta N_{\text {cycle }}$ 에 포함된 각 위상항 $(\mathrm{X}$ $=\mathrm{pp}, \mathrm{spin}, \mathrm{ecc}, \mathrm{tm}, \mathrm{tidal})$ 의 기여는 식 (21)에서 정의된 각 위상항과 다음과 같은 관계식으로 주어진다.

$$
\begin{aligned}
\Delta N_{\text {cycle }}^{X}= & \frac{1}{2 \pi}\left[\Delta \Psi^{X}(f)-\Delta \Psi^{X}\left(f_{0}\right)\right. \\
& \left.+\left(f_{0}-f\right) \frac{d \Psi^{X}}{d f_{0}}\right] .
\end{aligned}
$$

여기서 식 (21) 의 $\phi_{c}$ 와 $t_{c}$ 는 임의로 설정할 수 있으므로 $f_{0}$ 에서 $\Delta N_{\text {cycle }}^{X}=d\left(\Delta N_{\text {cycle }}^{X}\right) / d f=0$ 이 되도록 설정하였다. Fig. 4 에서는 조력항의 측정 가능성을 검토하기 위해 점입 자근사항과 조력항만 비교하였다. $\Delta \Psi_{3.5 \mathrm{PN} \text { only }}^{\mathrm{pp}}$ 는 포스트 뉴턴 표준 점입자근사 3.5 차항만 고려한 값이며, $\Delta \Psi_{6 \mathrm{PN}}^{\mathrm{tidal}}$ 는 식 (22)에 주어진 5,6차 조력항을 고려한 값이다. Fig. 4 에서 $f_{\mathrm{GW}}$ 가 증가할 수록 $\Delta \Psi_{6 \mathrm{PN}}^{\mathrm{tidal}}$ 이 $\Delta \Psi_{3.5 \mathrm{PN} \text { only }}^{\mathrm{pp}}$ 에 근접함을 확인할 수 있고, 조력항의 기여도는 $f_{\mathrm{GW}} \sim 600 \mathrm{~Hz}$ 근처에 서 $\Delta N_{\text {cycle }} \sim 0.5$ 에 도달하므로 $f_{\mathrm{GW}}$ 가 $600 \mathrm{~Hz}$ 이상일때 중요하게 됨을 확인할 수 있다 [13]. $\Delta N_{\text {cycle }}=0.5$ 이면 보강과 상쇄 간섭이 서로 바뀌어 관측이 용이하게 된다.

\section{V. 중성자별 상태방정식과 조력 변형성}

본 연구에서 선택한 다양한 상태방정식에 의한 단일 중 성자별의 조력 러브수 $\left(k_{2}\right)$ 와 조력 변형성 $(\lambda, \Lambda)$ 이 Figs. 5 , 6 및 7에 정리 되어 있다.

Fig. 5 의 (a)에서 작은 질량 및 큰 질량에서 $k_{2}$ 의 값이 모두 감소함을 확인할 수 있으며, (b) 에서 $M / R$ 의 값이 작은 경우와 큰 경우 모든 모델의 $k_{2}$ 값이 수렴함을 확인할 수 있다. 그런데, 연한 상태방정식 $\mathrm{ALF} 2$ 와 단단한 상태 방정식 MS1 및 MS1b의 경우 $k_{2}$ 값의 범위가 중복되므로 $k_{2}$ 를 이용하여 연한 상태방정식과 단단한 상태방정식을 구분하는 것은 어렵다.

Fig. 6 에서 연한 상태방정식(KIDS, MPA1, AP4, ALF2) 과 단단한 상태방정식 $(\mathrm{MS} 1, \mathrm{MS} 1 \mathrm{~b})$ 의 $\lambda$ 값 차이가 커서 구분이 가능함을 알 수 있다. (a) 에서 보면 평균적으로 대부분의 중성자별 질량 영역에서 단단한 상태방정식의 $\lambda$ 값이 연한 상태방정식의 2 배 이상으로 구분된다.

Fig. 7에서 단단한 상태방정식이 상대적으로 큰 $\Lambda$ 값을 주기는 하지만, 연한 상태방정식 사이에서도 $\Lambda$ 값의 차이가
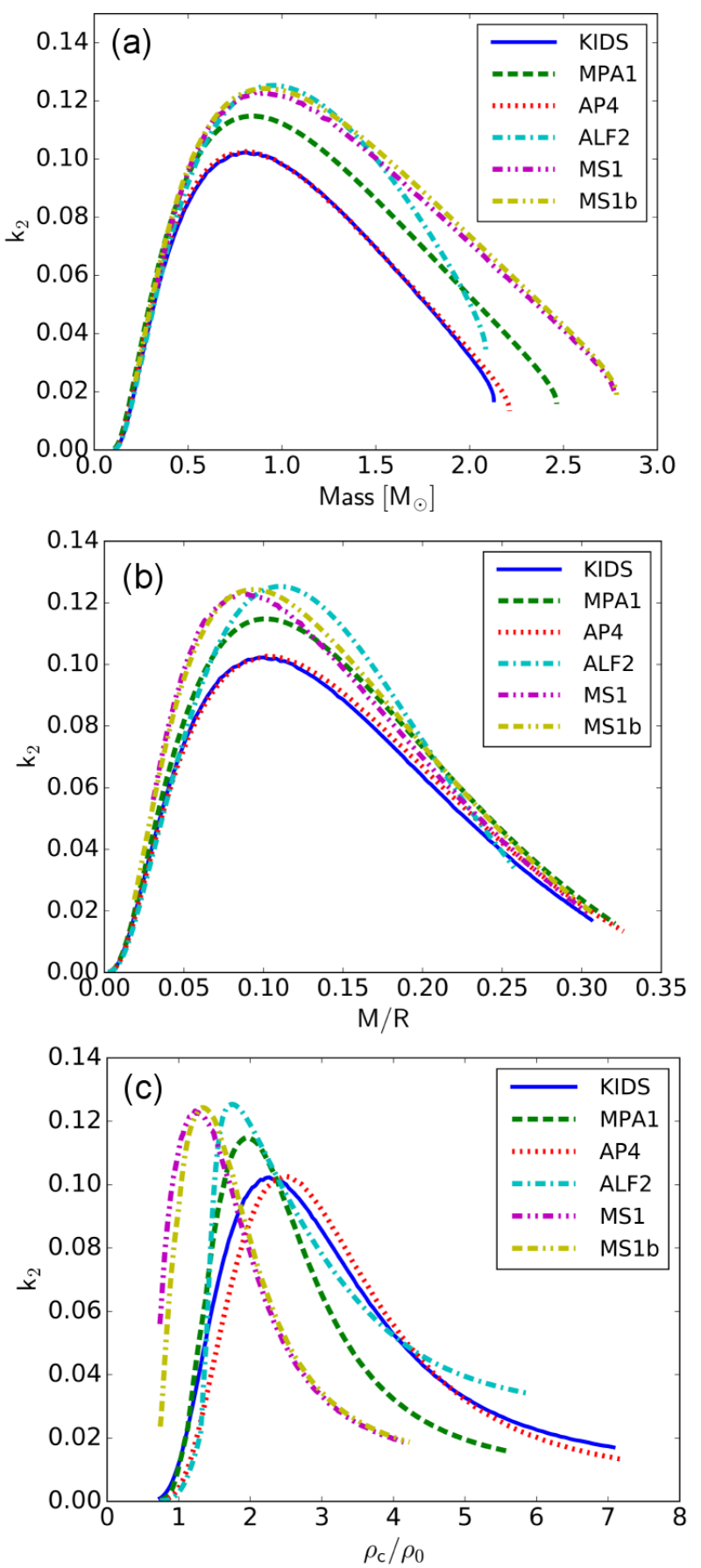

Fig. 5. (Color online) Tidal Love number $\left(k_{2}\right)$ of a single neutron stars. (a) $k_{2}$ vs. Mass, (b) $k_{2}$ vs. $\mathrm{M} / \mathrm{R}$, and (c) $k_{2}$ vs. $\rho_{c} / \rho_{0}$.

많이 나는 것을 확인할 수 있다. 특히 (a) 로부터 중성자별의 질량이 작은 경우 중력파를 이용한 $\Lambda$ 값의 측정으로 다양한 상태방정식을 보다 쉽게 검증할 수 있음을 확인할 수 있다. 일차적으로 수평선으로 표시된 GW170817의 $\Lambda$ 값(중성 자별의 질량을 $1.4 M_{\odot}$ 로 가정한 경우) 상한과 비교하면 단단한 상태방정식 $(\mathrm{MS} 1, \mathrm{MS} 1 \mathrm{~b})$ 이 제외됨을 알 수 있으며, 

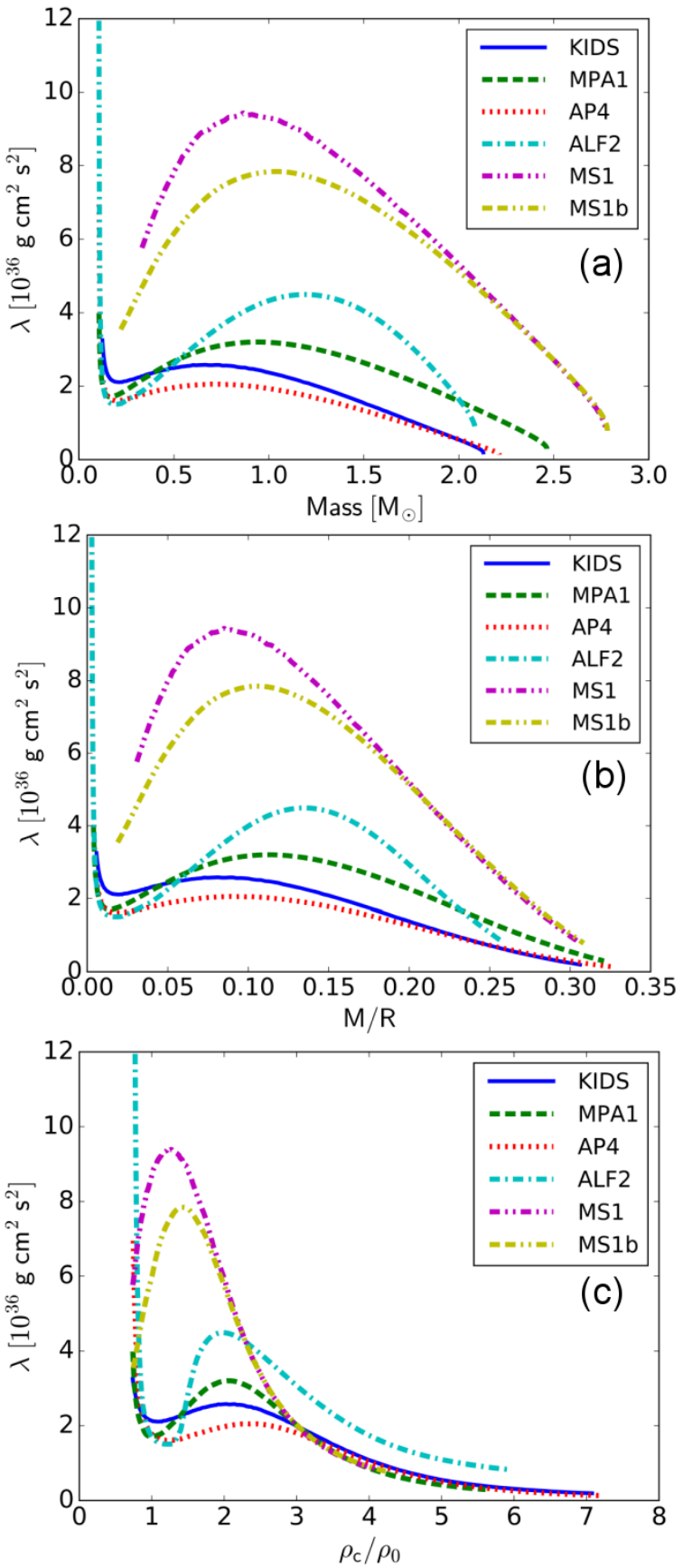

Fig. 6. (Color online) Tidal deformability $(\lambda)$ of a single neutron star. (a) $\lambda$ vs. Mass, (b) $\lambda$ vs. $\mathrm{M} / \mathrm{R}$, and (c) $\lambda$ vs. $\rho_{c} / \rho_{0}$.

보다 정밀한 측정이 이루어지면 연한 상태방정식을 검증할 수 있음을 확인할 수 있다.

Fig. 8에 관측된 GW170817의 질량 분석 결과를 이용 하여 (a) 전체질량이 $M_{\text {total }}=2.74 M \odot$ 인 두 중성자별의 $\Lambda_{1}, \Lambda_{2}$ 및 (b) 쳐프질량 $M_{\text {chirp }}=1.188 M_{\odot}$ 인 경우 질량비 $\left(M_{2} / M_{1}\right)$ 에 따른 $\tilde{\Lambda}$ 가 정리되어 있다 [13]. 이 그림에서 대부분의 질량 영역에서 단단한 상태방정식 $(\mathrm{MS} 1, \mathrm{MS} 1 \mathrm{~b})$
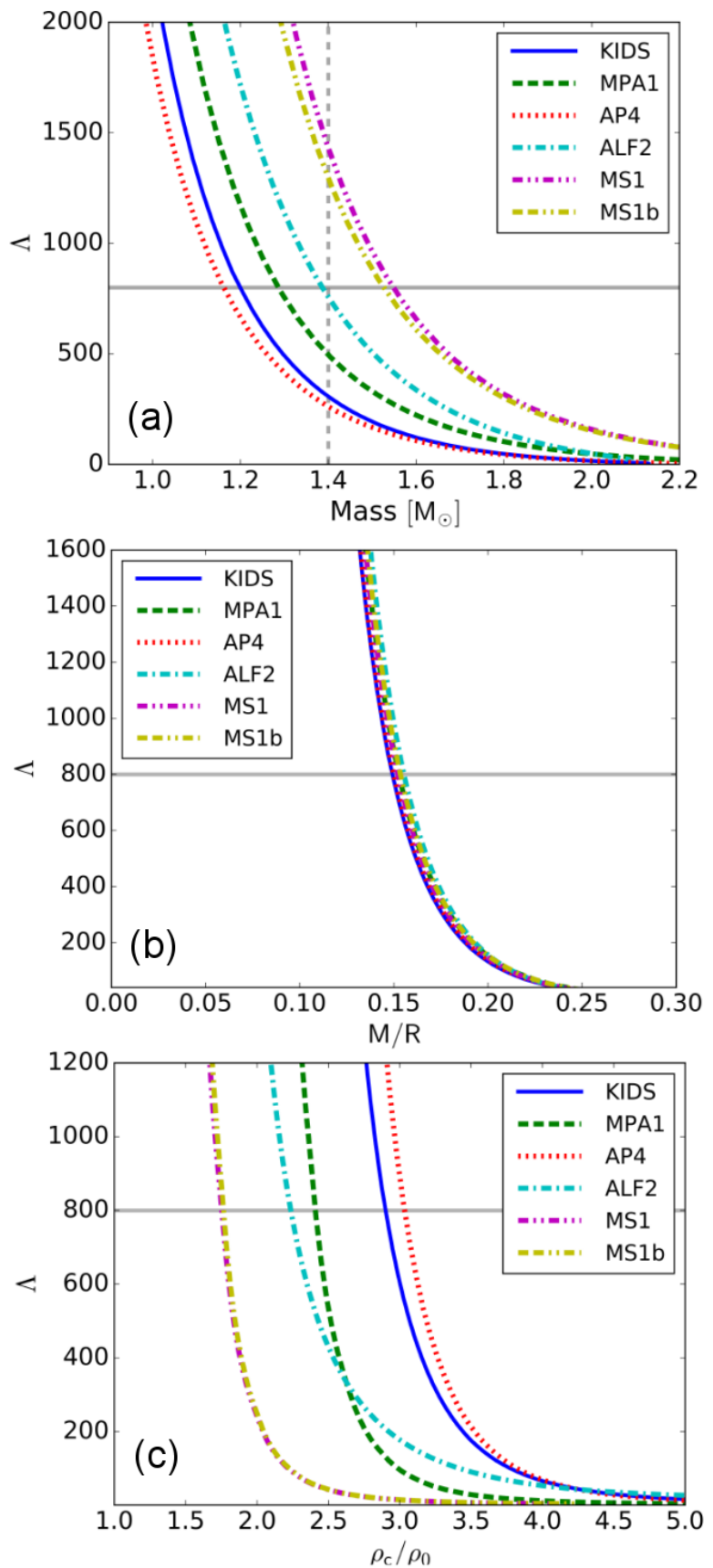

Fig. 7. (Color online) Dimensionless tidal deformability $(\Lambda)$ of a single neutron star. Horizontal grey lines in all panels indicate the upper limit of $\Lambda$ with $M=1.4 M_{\odot}$ obtained from GW170817. In (a), cross points of various curves with a vertical dashed line correspond to $\Lambda$ at $M=1.4 M_{\odot}$. (a) $\Lambda$ vs. Mass, (b) $\Lambda$ vs. $\mathrm{M} / \mathrm{R}$, and (c) $\Lambda$ vs. $\rho_{c} / \rho_{0}$.

가 제외됨을 알 수 있다. 또한 GW170817의 상한값 아래 에 연한 상태방정식의 $\Lambda$ 값이 넓은 영역에 퍼져 있으므로, 보다 정밀한 측정이 이루어지면 중력파를 이용하여 연한 상태방정식을 검증할 수 있음을 확인할 수 있다. 

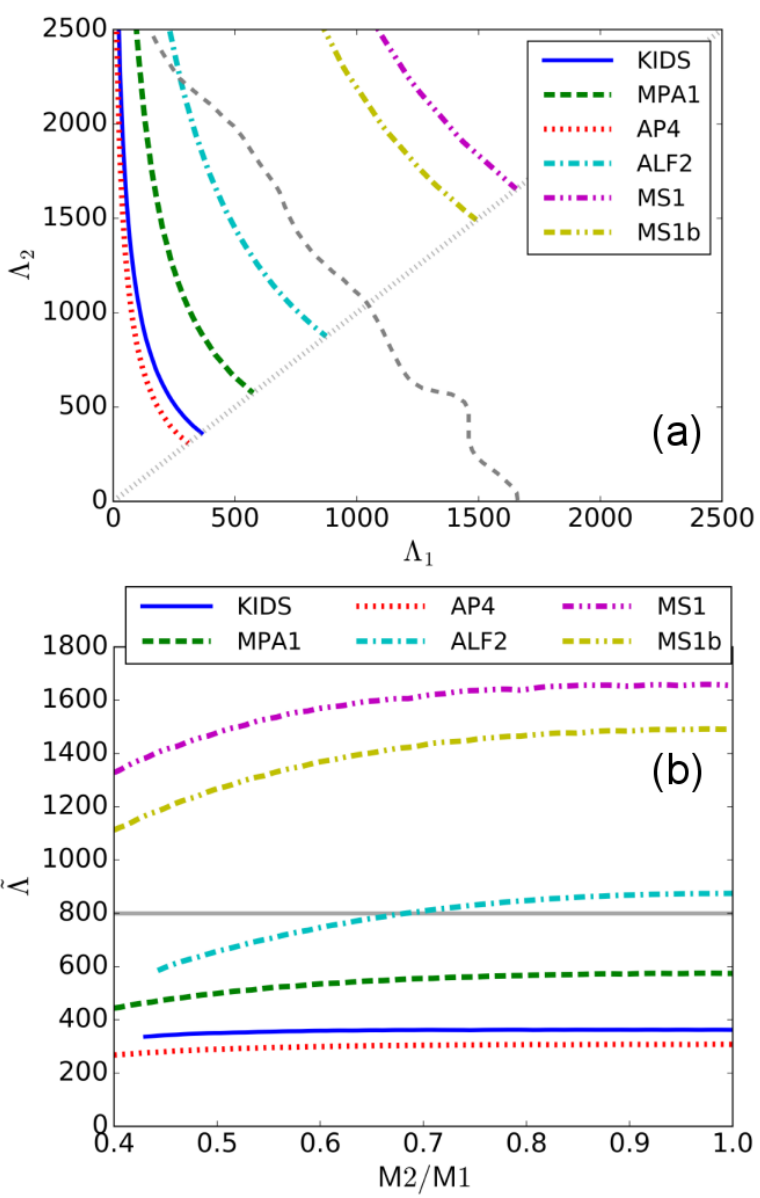

Fig. 8. (Color online) dimensionless tidal deformabilities in a binary system. A grey dashed curve in (a) represents the $90 \%$ confidence upper limit of $\tilde{\Lambda} \leq 800$ in the $\Lambda_{1-}$ $\Lambda_{2}$ space (i.e., the region below the curve corresponds to $\tilde{\Lambda} \leq 800$ with $90 \%$ confidence) and a grey horizontal solid line in (b) represents the upper limit of $\tilde{\Lambda}$ for GW170817 [13]. Total mass $M_{\text {total }}=2.74 M_{\odot}$ is used for (a), and chirp mass $M_{\text {chirp }}=1.188 M_{\odot}$ is used for (b). (a) $\tilde{\Lambda}$ in the $\Lambda_{1}-\Lambda_{2}$ space, (b) $\tilde{\Lambda}$ vs. $M_{2} / M_{1}$.

\section{VI. 결론 및 전망}

본 연구에서는 이론으로 예측된 중성자별 최대 질량이 관측으로 확인된 중성자별의 질량 $2 M_{\odot}$ 보다 큰 값을 주는 상태방정식 중에서 대표적인 단단한 상태방정식과 연한 상태방정식을 이용하여 중력파를 통하여 중성자별 내부 구조를 연구할 수 있는 가능성을 논의하였다. 본 연구에 포 함된 단단한 상태방정식 (MS1, MS1b) 과 연한 상태방정식 (KIDS, MPA1, AP4, ALF2)의 경우 예측된 $\Lambda$ 값에 차이 가 많이 나서, GW 170817 의 관측 결과 $\tilde{\Lambda} \leq 800$ 으로부터 단단한 상태방정식을 제외시킬 수 있음을 확인하였다. 또한 연한 상태방정식으로 예측된 $\Lambda$ 값도 넓은 영역에 분포하여,
보다 정밀한 중력파 관측이 이루어지면 중력파를 이용하여 연한 상태방정식도 검증할 수 있음을 확인하였다.

GW170817의 관측 이후, $\Lambda$ 에 대한 많은 연구가 이루어 졌다. Ref. [39]는 카이럴 유효장론 (chiral effective field theory) 및 비섭동 양자색소역학(non-perturbative QCD) 상태방정식을 폴리트롭 구조로 근사하여 관측된 $\tilde{\Lambda}$ 와 비 교함으로써 $1.4 M_{\odot}$ 중성자별의 반경이 $11.4 \sim 13.4 \mathrm{~km}$ 에 분포함을 보였다. 또한 Ref. [40]에서는 카이럴 유효장론의 결과를 비상대론적 스컴힘 모형을 이용하여 확장하였으며, 통계학적 방법으로 중성자별의 질량에 따른 반지름과 조력 변형성의 분포를 연구하였고, $1.4 M_{\odot}$ 중성자별의 반지름과 조력 변형성의 상관관계를 보여주었다. 이 결과는 중력파 를 이용하여 중성자별의 반경을 추정할 수 있는 가능성을 보여주고 있다.

정상 핵밀도 $\left(n_{0} \approx 0.16 \mathrm{fm}^{-3}\right)$ 에서 정의된 핵대칭에 너지 $\left(S_{v}\right)$ 와 핵대칭에너지의 밀도에 대한 미분값 $(L)$ 은 핵물리학에서 중요한 상수이다 [41]. 핵천체 물리학의 관 점에서 핵밀도 미분값 $(L)$ 은 $1.4 M_{\odot}$ 중성자별의 반지름과 $R \sim L^{1 / 4}$ 해당되는 상관관계가 있고 $[42,43]$, 핵구조 물 리학 연구와 관련해 ${ }^{208} \mathrm{~Pb}$ 의 중성자 표면 두께 $\left(\Delta R_{n p}\right)$ 를 이해하는 매계변수로 이용되어 $\Delta R_{n p}=a+b L$ 과 같은 강한 선형 상관관계를 갖고 있다 [44]. 이러한 상관관계 를 이용해 Ref. [45]는 관측된 $\tilde{\Lambda}$ 값을 이용하여 ${ }^{208} \mathrm{~Pb}$ 의 중성자 표면 두께를 구할 수 있는 가능성도 보여주었다. 거시적으로 중성자별의 조력 변형성은 중성자별의 크기와 관련하여 $\Lambda \sim R_{1.4 M_{\odot}^{7.5}}$ 와 같은 상관관계가 존재한다는 것이 밝혀졌다 [39]. 이러한 연구들을 통해 중력파를 통한 조력 변형성 측정의 중요성을 핵물리학의 관점에서 확인할 수 있다.

2018 년 후반기에 가동예정인 라이고의 3 번째 관측가동에 서는 더욱 향상된 검출기 성능과 함께 관측기간이 1 년으로 늘어나 검출가능한 신호의 기대치가 더욱 늘어날 것으로 예상된다 [46]. 중성자별 쌍성계에 대한 현재의 이론적 모 델과 검출기 성능 목표치를 고려하면 3 번째 관측가동에서 관측가능한 중성자별 쌍성계의 기대값은 $1 \sim 50$ 개이다 [46]. 또한 향상된 버고 (Virgo) 검출기가 동시 관측에 들어 가므로, 향상된 3 개의 중력파 검출기 (라이고 2 기, 버고 1 기) 를 통해 다수의 중력파신호에 대한 중력파원의 위치정보를 더욱 정확히 알 수 있다. 중력파 관측을 통한 중력파원에 대한 위치정보는 전자기파 후속관측을 위한 필수정보이며, 중성자별 쌍성의 병합과정 이후 발생되는 전자기파 관측에 활용되어 중력파원 연구뿐만 아니라 후속관측되는 고에너 지 천체에 매우 중요한 역할을 하게된다. 2024년이후 라이 고와 버고의 검출기가 목표 성능에 다다를 경우, 최대 2-3 일에 한개의 중력파 신호를 관측할 수 있다. 또한 이시기는 
일본의 카그라 $(\mathrm{KAGRA})$ 검출기가 실제적인 동시 관측을 할 것으로 예상되므로 관측된 중력파 신호에 대해 더욱 정밀 한 물리정보를 얻을 것으로 예상되며, 이를 통해 측정된 $\Lambda$ 로부터 상태방정식에 대한 정밀한 연구가 이루어질 것으로 기대된다.

\section{ACKNOWLEDGEMENTS}

This work was supported by a 2-Year Research Grant of Pusan National University.

\section{REFERENCES}

[1] B. P. Abbott et al. (LIGO Scientific Collaboration and Virgo Collaboration), Phys. Rev. Lett. 116, 061102 (2016).

[2] B. P. Abbott et al. (LIGO Scientific Collaboration and Virgo Collaboration), Phys. Rev. Lett. 116, 241103 (2016).

[3] B. P. Abbott et al. (LIGO Scientific Collaboration and Virgo Collaboration), Phys. Rev. Lett. 118, 221101 (2017).

[4] B. P. Abbott et al. (LIGO Scientific Collaboration and Virgo Collaboration), Phys. Rev. Lett. 119, 141101 (2017).

[5] H. M. Lee, New Phys.: Sae Mulli 66, 258 (2016).

[6] J. J. Oh and G. Kang, New Phys.: Sae Mulli 66, 264 (2016).

[7] H. J. Paik, H. M. Lee, K. Cho and J. Kim, New Phys.: Sae Mulli 66, 272 (2016).

[8] S. H. Oh, E. J. Son, W. Kim, J. J. Oh, H. W. Lee, J. Kim and Y.-M. Kim, New Phys.: Sae Mulli 66, 283 (2016).

[9] C. Kim, H. S. Cho, G. Kang, H. W. Lee, C.-H. Lee and H. K. Lee, New Phys.: Sae Mulli 66, 293 (2016).

[10] H.-S. Cho, J. Korean Phys. Soc. 69, 884 (2016).

[11] H.-S. Cho, J. Korean Phys. Soc. 70, 735 (2017).

[12] H.-S. Cho and C.-H. Lee, J. Korean Phys. Soc. 72, 1 (2018).

[13] B. P. Abbott et al. (LIGO Scientific Collaboration and Virgo Collaboration), Phys. Rev. Lett. 119, 161101 (2017).
[14] LIGO Scientific Collaboration and Virgo Collaboration et al., Astrophys. J. Lett. 848, L12 (2017).

[15] E. Troja, L. Piro, H. van Eerten, R. T. Wollaeger and M. Im et al., Nature 551, 71 (2017).

[16] The LIGO Scientific Collaboration and The Virgo Collaboration et al., Nature 551, 85 (2017).

[17] T. Hinderer, Astrophys. J. 677, 1216 (2008).

[18] T. Hinderer, B. D. Lackey, R. N. Lang and J. S. Read, Phys. Rev. D 81, 123016 (2010).

[19] M. Favata, Phys. Rev. Lett. 112, 101101 (2014).

[20] T. Damour and A. Nagar, Phys. Rev. D 80, 084035 (2009).

[21] L. Wade, J. D. E. Creighton, E. Ochsner, B. D. Lackey and B. F. Farr et al., Phys. Rev. D 89, 103012 (2014).

[22] É. É. Flanagan and T. Hinderer, Phys. Rev. D 77, 021502 (2008).

[23] B. D. Lackey and L. Wade, Phys. Rev. D 91, 043002 (2015).

[24] K. Kim, H. K. Lee and J. Lee, Int. J. Mod. Phys. E 26, 1740011 (2017).

[25] W.-G. Paeng, T. T. S. Kuo, H. K. Lee, Y.-L. Ma and M. Rho, Phys. Rev. D 96, 014031 (2017).

[26] P. Demorest, T. Pennucci, S. M. Ransom, M. S. E. Roberts and J. W. T. Hessels, Nature 467, 1081 (2010).

[27] J. Anoniadis, P. C. C. Freire, N. Wex, T. M. Tauris and R. S. Lynch et al., Science 340, 1233232 (2013).

[28] A. W. Steiner, J. M. Lattimer and E. F. Brown, Astrophys. J. 722, 33 (2010).

[29] F. Özel and P. Freire, Ann. Rev. Astron. Astrophys. 54, 401 (2016).

[30] P. Papakonstantinou, T.-S. Park, Y. Kim and C. H. Hyun, Phys. Rev. C 97, 014312 (2018).

[31] H. Gil, Y. Oh, C. H. Hyun and P. Papakonstantinou, New Phys.: Sae Mulli 67, 456 (2017).

[32] M. Dutra, O. Lourenco, J. S. Sá Martins, A. Delfino, J. R. Stone and P. D. Stevenson, Phys. Rev. C 85, 035201 (2012).

[33] H. Müther, M. Prakash and T. L. Ainsworth, Phys. Lett. B 199, 469 (1987).

[34] A. Akmal, V. R. Pandharipande and D. G. Ravenhall, Phys. Rev. C 58, 1804 (1998). 
[35] M. Alford, M. Braby, M. Paris and S. Reddy, Astrophys. J. 629, 969 (2005).

[36] H. Müller and B. D. Serot, Nucl. Phys. A 606, 508 (1996).

[37] A. E. H. Love, Proc. R. Soc. Lond. A 82, 73 (1909).

[38] S. Postnikov, M. Prakash and J. M. Lattimer, Phys. Rev. D 82, 024016 (2010).

[39] E. Annala, T. Gorda, A. Kurkela and A. Vuorinen, Phys. Rev. Lett. 120, 172703 (2018).

[40] Y. Lim and J. W. Holt, Phys. Rev. Lett., to be published; arXiv:1803.02803 (2018).

[41] J. M. Lattimer and Y. Lim, Astrophys. J. 771, 51 (2013).

[42] J. M. Lattimer and M. Prakash, Phys. Rept. 442, 109 (2007).

[43] Y. Lim, C. H. Hyun and C-H. Lee, Int. J. Mod. Phys. E 26, 1750015 (2017).

[44] M. Centelles, X. Roca-Maza, X. Viñas and M Warda, Phys. Rev. Lett. 102, 122502 (2009).

[45] F. J. Fattoyev, J. Piekarewicz and C. J. Horowitz, Phys. Rev. Lett. 120, 172702 (2018).

[46] B. P. Abbott et al., (KAGRA Collaboration, LIGO Scientific Collaboration and Virgo Collaboration), Living Rev. Relativ. 21, 3 (2018).
김영민 박사는 부산대학교 물리학과에서 이학사, 석사, 박사 학위를 받고, 서울대학교, 부산대학교 를 거쳐 현재 울산과학기술원에서 박사후 연구 원으로 재직중이다.

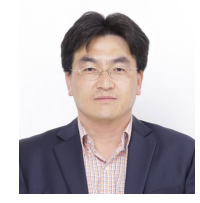

곽규진 교수는 서울대학교 물리학과에서 이학사, 석사 학위, 뉴욕주립대학교 스토니부룩 캠퍼스 에서 박사 학위를 받고, 조지아 대학교 및 한국천 문연구원을 거쳐 2012년부터 울산과학기술원에 재직 중이다.

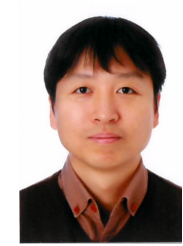

임연환 박사는 서울대학교 자연과학부에서 이학 사, 뉴욕주립대학교 스토니부룩 캠퍼스에서 박사 학위를 받은 후 대구대학교, 중이온 가속기 사업 단을 거쳐 현재 텍사스 A\&M 대학교 사이클로 트론 연구소에 박사후 연구원으로 재직 중이다.

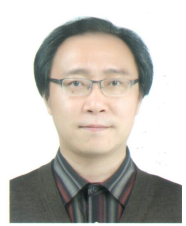

현창호 교수는 서울대학교 물리학과에서 이학사, 석사, 박사 학위를 받고 성균관대학교에서 박사 후 연구원을 거친 후 2008 년부터 현재까지 대구 대학교 물리교육과에 재직 중이다.

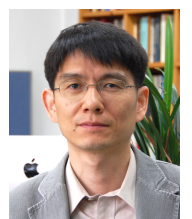

이창환 교수는 서울대학교 물리학과에서 이학사, 석사, 박사 학위를 받고, 뉴욕주립대학교 스토니 부룩 캠퍼스, 고등과학원 및 서울대 $\mathrm{BK}$ 물리사업 단을 거쳐 2003년부터 부산대 물리학과에 재직 중이다. 